\title{
Patient Monitoring System for Smart Multi Speciality Healthcare Centre using Internet of Things (IoT)
}

\author{
K. Thiyagarajan, K. Mohan Kumar
}

\begin{abstract}
A healthcare centre is an organization in which effective treatment is given to patient for their health problems using specialized staff and equipments. Here patient's information is stored in computer databases and retrieved when the further treatment is needed. At present all the information are stored into database and retrieved with human intervention. The human part of this system is error prone and often leads to inconsistencies in treatment. It may create severe problems in patient's health related problems. With the advent of technology in the modern era these problems can be eradicated and improvements can be made in patient care by eliminating the unnecessary burden. Even though modern technology is often used in hospitals for many purposes, it is not concentrated in the reduction of patients waiting time. The waiting time cannot be taken lightly as it leads to increase in their blood pressure and mismanage their valuable time, also increasing healthcare centre's expenses in an indirect manner by providing water facility, air conditioning facility etc. The manual token issuing system maintained in many healthcare centres is obsolete due to the improper handling of the queue by hospital staff. If it is automated through IoT, these problems will be sorted out completely. If a system is designed to reduce the patient's unnecessary waiting time, it will be of immense importance for both the healthcare centre management and the public. So, this paper provides a solution to eradicate this problem
\end{abstract}

Keywords: Internet of Things (IoT), Hospital Management System, Waiting Time, Cost Analysis, Patient Queue Management, Cloud Based Medical History (CBMH)

\section{INTRODUCTION}

The day to day activities of a hospital such as storing patient's information and their treatment details, doctor's management etc., is maintained through a software system called "HOSPITAL MANAGEMENT SYSTEM (HMS)". It is designed to manage financial, administrative and service departments of the hospital. Hospital management system

Revised Manuscript Received on February 05, 2020.

* Correspondence Author

K. Thiyagarajan*, research scholar, Rajah Serfoji Government College, Thanjavur, Affiliated to Bharathidasan University, Tiruchirappalli-620024, Tamil Nadu, India. E-mail: profktr@gmail.com

Dr. K. Mohan Kumar, Head Of Department, Department of Computer Science, Rajah Serfoji Government College, Thanjavur, Affiliated to Bharathidasan University, Tiruchirappalli-620024, Tamil Nadu, India. E-mail: tnjmohankumar@gmail.com

(C) The Authors. Published by Blue Eyes Intelligence Engineering and Sciences Publication (BEIESP). This is an open access article under the CC BY-NC-ND license (http://creativecommons.org/licenses/by-nc-nd/4.0/) coordinates the different operational areas of the multi-speciality hospital to provide convenient administration. The hospital management system offers data handling and retrieval which allows us to keep archive of relevant information. It reduces form-filling and book-keeping procedures by uploading it to a database and allowing easy retrieval and modification. It also allows easy but secured access to critical data thus enabling the management to take better decisions on matters involving time. It is also very volatile and damage free data when it goes to digital. Hospital should store all details including patient details, their treatment details which are based on test reports of patients conducted in the pathology lab of the hospital. The information of the hospital patients should be kept up-to-date in the system for future use. In recent years more improvements have been done in hospital management. Recent technological advancements helped hospitals to provide better healthcare, better treatment, better user experience, better pathology and better use of hospital services. Making the staff specialized in new fields of the medical department made the management of the hospital system very complicated. Therefore, modernized automatic system is needed for the efficient functioning of the hospital system.

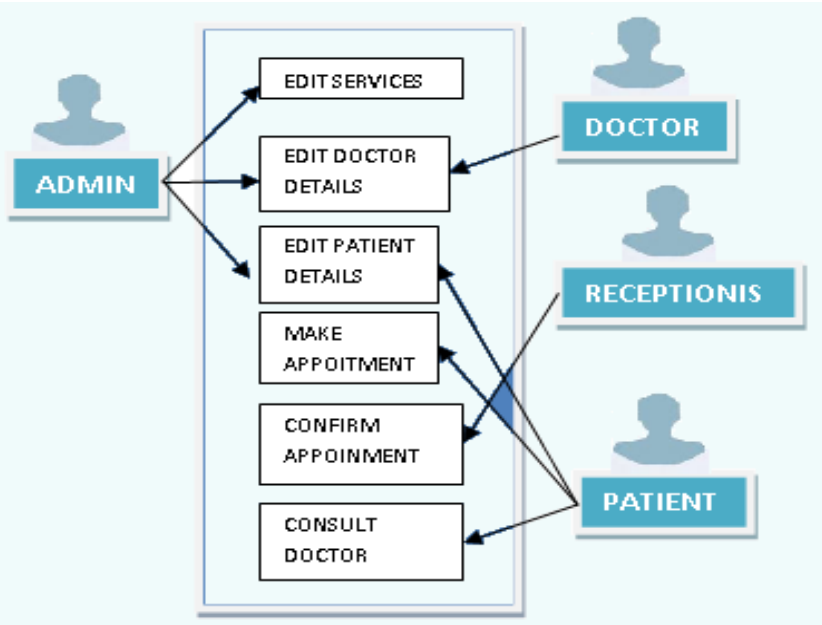

Fig 1: Elements of HMS

Hospital management system may be defined in a number of different ways and may function in different methods for different sectors of the hospital. It mainly aims at coordinating the different departments and documenting them in a presentable way.

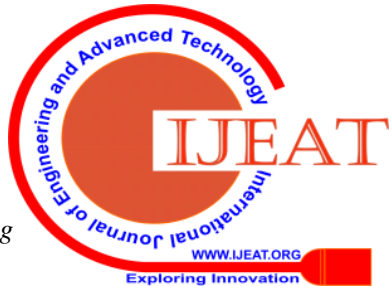


The above Figure1 shows the various people involving in the present hospital management system to take care of each and every element of the hospital

The hospital management system automates the filing and retrieval of data in the hospital. It also makes book-keeping and updating of data simpler. It also aids the staff management, inventory management and pharmacy management. It also computes the resource management required for optimal activity of the hospital.. The patient-centric and well-managed hospital management system will ensure a better work environment for their employees. The following figure 2 shows the workflow of present HMS

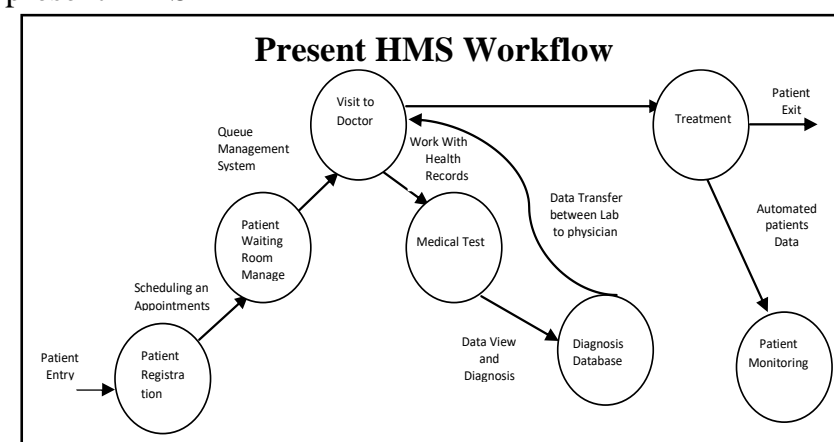

Figure: 2. HMS Workflow

Patient registration and filling up of all the necessary data about patients are done. The next stage is patient waiting room management. Here water facility, air conditional facility and entertainment facility like keeping news papers, television facility are provided. The next stage is attending the patient by the doctor. Here the doctor consult the patients and send for medical test if they need. Then medical test is conducted for the patient and stored in the diagnosis database. Then with the report the patient consult the doctor again for treatment. The patient monitoring part of the system stores the treatment details such as the list medicines and the dosage details. These details are very much useful for further diagnosis. These stages are done previously with lot of paper work. After the implementation of computerization the paper works are completely stopped. Doctors spend more time on patients' treatment rather than documentation. If something is required in a written form, they can get it from patients' database easily. Even though it is effective there is no methodology to reduce the patient waiting time and still they are maintaining the manual system partially.

A hospital relies mainly on the cooperation of the different entities in the hospital system. This often requires proper communication between different individuals such as the patient, the nurse, and the different specialized physicians. In this case verbal communication is often misinterpreted. It affects the performance of HMS. Therefore the use of advanced technology in both communication and treatment of a patient is necessary.

Time management is the most important attribute which defines the optimized functioning of the hospital. Judicious use of time by the hospital management system reduces the burden on both the patients as well as doctors. Queuing documentation is not yet easy and time consuming process in HMS. It increases the stress of patients. Studies show that the physical and mental irritation that one receives while standing in a queue increases their blood pressure and has a negative effect on their treatment [1].

The use of an IoT based system for the monitoring of a queue provides lot of benefits to the patients [2]. The following benefits will be harvested while implementing the proposed system:

- Intangible benefits include the benefits that cannot be physically measured such as the satisfaction of a customer due to a reduced waiting time, immediate medical attention and easier queue maintenance. This makes the more sophisticated HMS environment.

- Tangible benefits include the cost benefits for the patients and the hospital management. These benefits can be calculated by using a cost analysis method.

- Health benefits include the benefits related to health such as reduce stress levels which occurs due to the elimination of a long queue in a hospital. This reduces blood pressure and anxiety.

So, this work concentrates the objectives and yields the expected output in optimum manner.

\section{REVIEW OF RELATED WORKS}

Ngorsed $\mathrm{M}$ and Suesaowaluk [3] presented an alternative system for queuing management that could reduce inconvenience to the public. With the help of a web application they have formulated a way in which the queuing system in a hospital environment can be modified so that all the different stakeholders in the process are benefitted. Sultan H. AlMotiri , Murtaza A. Khan,Mohammed A. AlGhamdi [4] developed a mobile application for health (m-health) monitoring system using IoT device which tracks patient vitals such as their heartbeat, pulse and blood pressure. Dr K. Mohan Kumar \& K. Thiyagarajan [5] gave an idea to maintain an optimum number of servers based on, on demand queue in a hospital environment. Different queuing models were studied and the waiting time optimized so as to give the queue which assures minimum cost to the hospital. The psychology change in people and the physical toil of the waiting process was studied by Norman, Donald \& A, Donald [6]. The use of mobile applications to manage queues and it's effects on businesses were studied by Khong, Yeen \& Ooi, Bee [7].

\section{METHODOLOGY}

The purpose of this paper is mainly to reduce the waiting time in a multi speciality healthcare centre by a queuing system with the help of IoT devices. When a patient feels unwell or requires the assistance of a doctor, they may use a mobile application to enroll themselves in the queue. The IoT with a mobile application generates their token number and keep them in the queue. The use of this virtual queue eliminates the need of the physical presence of the patient in the hospital. The queue position of the patient and the expected waiting time for their treatment is approximately calculated. These details send to the patient while they run their mobile application. 
The following Figure 3 shows the token issuing process of proposed Smart healthcare Management System (SHMS).

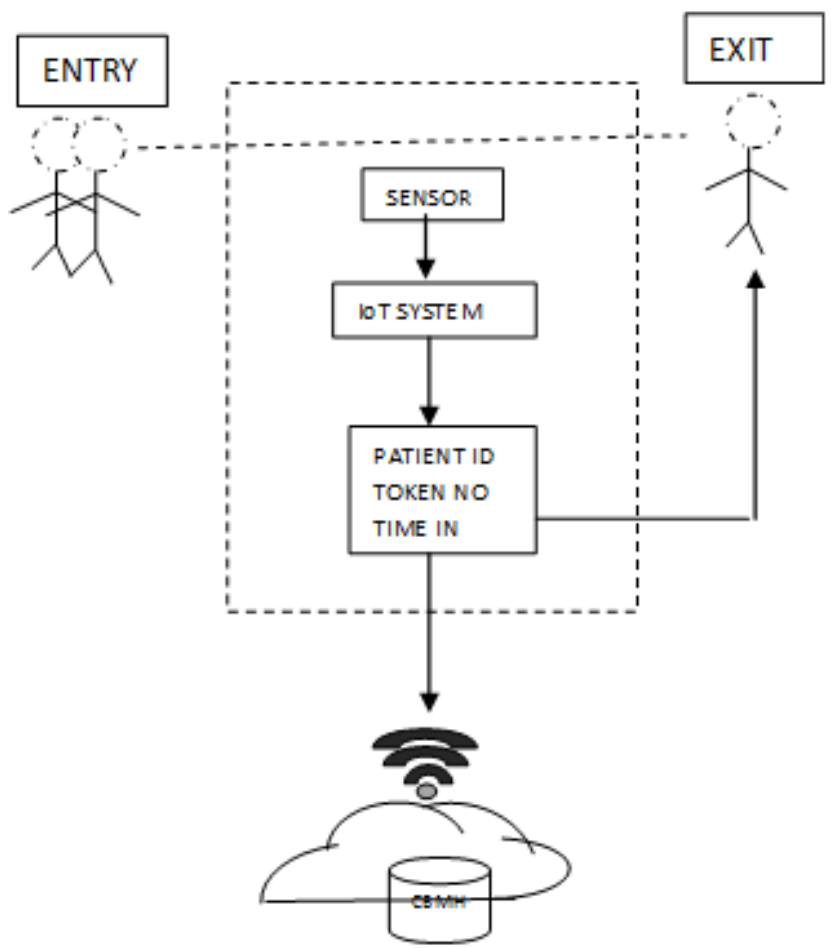

Figure 3: Proposed HMS Patient Queue Management

When a patient enter into the healthcare centre, the IoT device read patient's ID, then access the Cloud based Medical History (CBMH) and provide the treatment history of the old patient to the doctor. This activity eliminates the lengthy documentation process. Once the registration process is over, the patient is allowed to go anywhere. Patients physical presence is not necessary as the queue is virtual maintained by the IoT environment. This allows the patient to continue their work in their own premises. This reduces the stress of an individual because it eliminates the need of standing in a queue. On the other side the hospital management saves themselves from the position of spending money in order to provide facilities to the patients. Also, this makes effective crowd control and assures an error free queuing system. The use of this system therefore reduces the overhead cost for a patient by reducing the stressful procedures involved in healthcare centre's management. This process does not interfere with the treatment process to the patient and does not interfere with the quality of treatment to the patient.

The following Figure: 4 explains how the mobile application is executed when a patient runs the application installed in their mobile.

When the patient runs the application using their mobile, signal sent to the cloud and access the information with the help of registered mobile number as a key, then recognize their position and calculate their position value. The expected approximate waiting time is calculated and resends the signal to patient mobile with their position at present. It will be changed automatically when a doctor finished the consulting. Here the queue is maintained using the FIFO logic. So, the patient no needs to worry about their token position and do their duty without any wastage of time. The management also can able to reduce the extra cost incurred for the facilities needed for the patient.

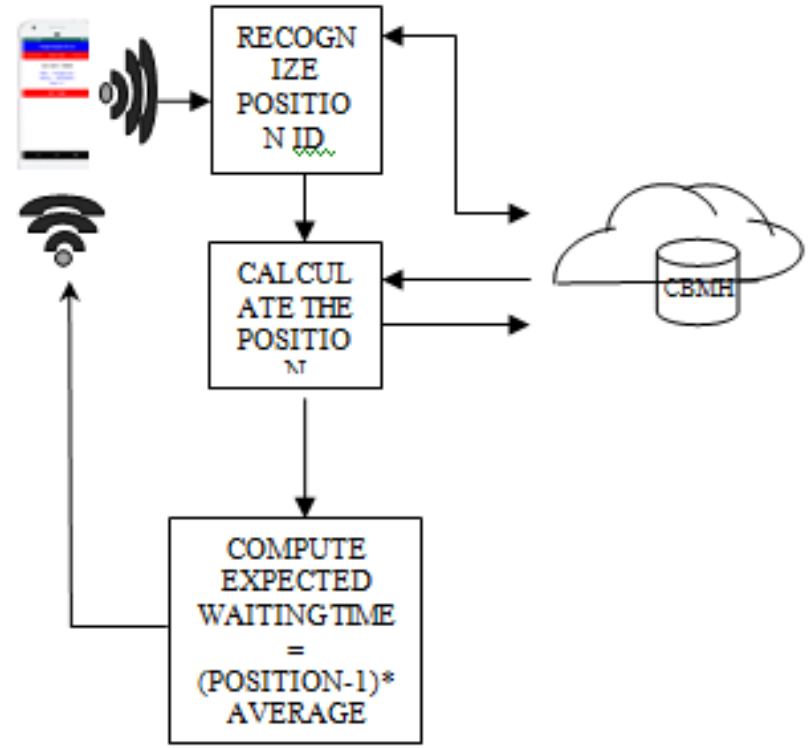

Figure 4: Patient Mobile Application

\section{RESULTS AND DISCUSSION}

\section{A. Annual cost analysis for Patient}

The following Table I shows the total waiting for 12 patients is 55 minutes for one hour consulting plan. Here nearly $92 \%$ is increased for one hour plan. Submission of the paper

Table I: Waiting time of patients

\begin{tabular}{|c|c|c|c|c|c|}
\hline S.No & $\begin{array}{l}\text { Entry } \\
\text { time }\end{array}$ & $\begin{array}{c}\text { Service } \\
\text { Start }\end{array}$ & $\begin{array}{c}\text { Service } \\
\text { End }\end{array}$ & $\begin{array}{c}\text { Waiting } \\
\text { time }\left(W_{t}\right)\end{array}$ & $\begin{array}{c}\text { IoT } \\
\text { Waiting } \\
\text { Time }\left(W_{i}\right)\end{array}$ \\
\hline 1 & 02:00:00 & 02:00:00 & 02:10:00 & 00:00:00 & 00:00:00 \\
\hline 2 & 02:05:00 & 02:10:00 & 02:20:00 & 00:05:00 & 00:05:00 \\
\hline 3 & 02:10:00 & 02:20:00 & 02:30:00 & 00:10:00 & 00:05:00 \\
\hline 4 & 02:15:00 & 02:30:00 & 02:40:00 & 00:15:00 & 00:05:00 \\
\hline 5 & 02:20:00 & 02:40:00 & 02:50:00 & 00:20:00 & 00:05:00 \\
\hline 6 & 02:25:00 & 02:50:00 & 03:00:00 & 00:25:00 & 00:05:00 \\
\hline 7 & 02:30:00 & 03:00:00 & 03:10:00 & 00:30:00 & 00:05:00 \\
\hline 8 & 02:35:00 & 03:10:00 & 03:20:00 & 00:35:00 & 00:05:00 \\
\hline 9 & 02:40:00 & 03:20:00 & 03:30:00 & 00:40:00 & 00:05:00 \\
\hline 10 & 02:45:00 & 03:30:00 & 03:40:00 & 00:45:00 & 00:05:00 \\
\hline 11 & 02:50:00 & 03:40:00 & 03:50:00 & 00:50:00 & 00:05:00 \\
\hline 12 & 02:55:00 & 03:50:00 & 04:00:00 & 00:55:00 & 00:05:00 \\
\hline \multicolumn{4}{|c|}{ Total } & 05:30:00 & 0:55:00 \\
\hline
\end{tabular}

The following Table II shows the cost wise analysis for the above situation. According to the Ministry of Statistics and Programme Implementation (MOSPI), the per capital income of India in the financial year 2017-18 was recorded for an Indian is Rs. 1,13,500 per annum[7]. So, the per capital income of Indian per day is Rs 310.95890411. 
Here the calculations are done using the following formula with this cost.

Average waiting time/person $\left(\mathbf{W}_{\text {sp }}\right)$

$=\Sigma \mathrm{W} /$ number of patients

Time wasted in one year $\left(\mathbf{T}_{\mathbf{s p}}\right)$

$=\mathrm{W}_{\mathrm{s}} \mathrm{X}$ No of Months $\mathrm{x}$ No. of Days in Year

Total expense in rupees $\left(\mathbf{T E}_{\mathbf{c}}\right)$

$=\mathrm{W}_{\mathrm{s}} \mathrm{X}$ No of Months $\mathrm{x}$ No. of Days in Year $\mathrm{x}\left(\mathrm{P}_{\mathrm{avg}}\right.$

Here,

$(\mathrm{P})=$ Patients

$\left(\mathrm{P}_{\text {avg }}\right)=$ Patients Average

Table II: Annual Cost analysis for a patient

\begin{tabular}{|l|l|l|}
\hline \multicolumn{1}{|c|}{ Patient } & \multicolumn{1}{|c|}{$\begin{array}{c}\text { Existing } \\
\text { method }\end{array}$} & \multicolumn{1}{c|}{$\begin{array}{c}\text { Proposed } \\
\text { IoT method }\end{array}$} \\
\hline Total waiting time & $05: 30: 00$ & $0: 55: 00$ \\
\hline $\begin{array}{l}\text { Average waiting } \\
\text { time/person (Ws) }\end{array}$ & $00: 27: 30$ & $0: 04: 35$ \\
\hline $\begin{array}{l}\text { Time wastage of } \\
\text { time for a year(Ts ) }\end{array}$ & $2007: 30: 00$ & $334: 35: 00$ \\
\hline $\begin{array}{l}\text { Total loss in rupees } \\
\text { per year(TEc) }\end{array}$ & 26010.41667 & 4335.069444 \\
\hline
\end{tabular}

So, IoT method saves Rs. 21,675.34723 in this circumstance to the patient. It is nearly $86 \%$ of cost is saved for an annum while implementing IoT method. The following Figure 5 clearly shows the effectiveness of IoT method.

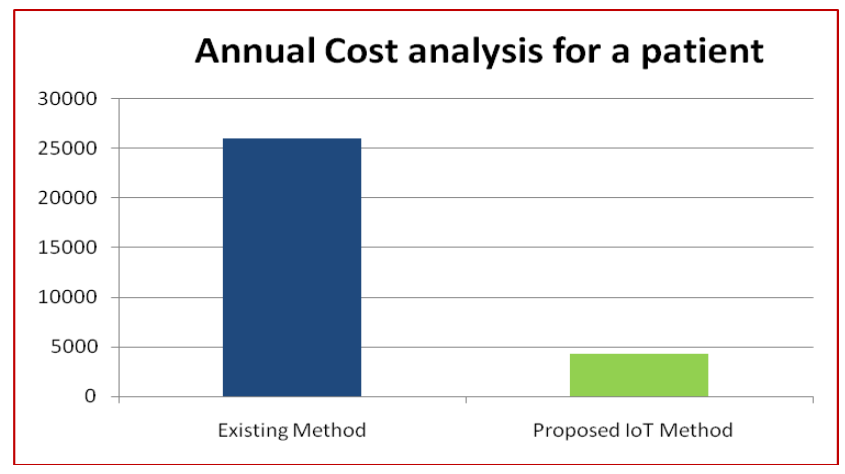

Figure 5 : Annual Cost Analysis Graph

\section{B. Cost Analysis for Healthcare Centre Management}

According to "The Economics of an Admissions Holding Unit” Dr Kraftin E. Schreyer and Dr Richard Martin, Temple University Hospital, Department of Emergency Medicine, the cost of operating the waiting room was calculated to be $\$ 10.40$ [8]. In Indian rupees it is Rs 735.17 per hour. The Table 1 shows the waiting time of existing method is 05:30:00. Here the calculations are done using the following formula with this cost.

Average waiting time/person $\left(\mathbf{W}_{\text {sh }}\right)$

$=\Sigma \mathrm{W} /$ number of patients

Time wasted in one year $\mathbf{( \mathbf { T } _ { \text { sh } } )}$

$=\mathrm{W}_{\mathrm{s}} \mathrm{X}$ No of Months $\mathrm{x}$ No.of Days in Year

Total Expense in rupees $\left(\mathbf{T E}_{\mathbf{h}}\right)$

$=\mathrm{W}_{\mathrm{s}} \mathrm{X}$ No of Months $\mathrm{X}$ No.of Days in Year $\mathrm{x}\left(\mathrm{P}_{\mathrm{avg}}\right.$ per hour)

Total loss in rupees $\left(\mathrm{T}_{\mathrm{e}}\right)$

$=\mathrm{W}_{\mathrm{s}} \mathbf{x} 12 \mathbf{x} 365 \mathrm{x}$ Cost of operating admission room .1hour)
Table III: Annual Cost analysis for a patient

\begin{tabular}{|l|c|c|}
\hline \multicolumn{1}{|c|}{ Hospital } & \multicolumn{1}{|c|}{$\begin{array}{c}\text { Existing } \\
\text { method }\end{array}$} & IOT method \\
\hline Total waiting time(Ws) & $05: 30: 00$ & $0: 55: 00$ \\
\hline $\begin{array}{l}\text { Time hours in one year } \\
\text { (Tsh) }\end{array}$ & $2007: 30$ & $334: .5833333$ \\
\hline $\begin{array}{l}\text { Equivalent number of } \\
\text { days }\end{array}$ & 83.64583333 & 13.94097222 \\
\hline $\begin{array}{l}\text { Total loss in rupees per } \\
\text { year( Ta) }\end{array}$ & 1475853.775 & 245975.6292 \\
\hline
\end{tabular}

So, IoT method saves Rs. 12, 29,878.1458 in this circumstance to the management. It is nearly $83.34 \%$ of cost is saved for an annum while implementing IoT method. The following figure 6: clearly shows the effectiveness of IoT method

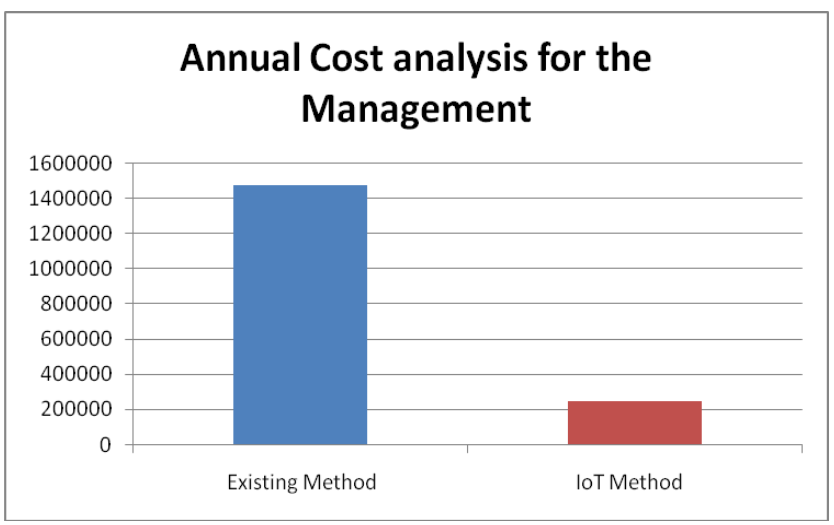

Figure 6: Annual Cost Analysis Graph.

\section{CONCLUSION \& FUTURE WORK}

The use of a mobile application with IoT environment in multi-speciality healthcare centre streamlines the existing queuing method and provides various benefits to the patients and healthcare centre management. It provides intangible, tangible and health benefits to the patient by simplifying the tedious process needed to avoid unnecessary waiting time. The cost analyses proved the effectiveness of the IoT system in clear manner. In future the modification of this mobile application with GPRS system will be implemented to identify the locations of the patient. It will be helpful to the management to track the movement of patient towards healthcare centre.

\section{REFERENCES}

1. Ahmad, B A et al. "An assessment of patient waiting and consultation time in a primary healthcare clinic." Malaysian family physician : the official journal of the Academy of Family Physicians of Malaysia vol. 12,1 14-21. 30 Apr. 2017

2. K. Mohan Kumar, K. Thiyagarajan, K. Geethanjali, "Effectiveness of IoT with Reference To Patient Waiting Time", International Journal of Computer Sciences and Engineering, Vol.6, Issue.8, pp.68-76, 2018

3. Ngorsed, Manoon \& Sueaowaluk, Poonphon. (2016). Hospital Service Queue Management System with Wireless Approach. 10.1007/978-981-10-0539-8_61.

4. Almotiri, Sultan \& Khan, Murtaza \& Alghamdi, Mohammed. (2016) Mobile Health (m-Health) System in the Context of IoT. 39-42. 10.1109/W-FiCloud.2016.24. 
5. K.Thiyagarajan, Dr.K.Mohan Kumar "Optimized Server Utilization In Multi Speciality Hospital By Using The Queuing Model Through IoT" International Journal of Scientific \& Technology Research Volume 8, Issue 10, OCTOBER 2019 pp 1038-1042

6. Norman, Donald \& A, Donald. (2008). The Psychology of waiting lines.

7. Khong, Yeen \& Ooi, Bee \& Tan, Kok \& Ibrahim, Salizatul Aizah \& Tee, Peck. (2017). E-Queue Mobile Application. SHS Web of Conferences. 33. 00033. 10.1051/shsconf/20173300033

8. India's per capita income grows by $8.6 \%$ to Rs 0.43 lakh in FY18 Times of India". The Times of India. Retrieved 8 January 2019.

9. Schreyer, Kraftin E, and Richard Martin. "The Economics of an Admissions Holding Unit." The western journal of emergency
medicine vol.
18,4
(2017):
553-558.

doi:10.5811/westjem.2017.4.32740

\section{AUTHORS PROFILE}

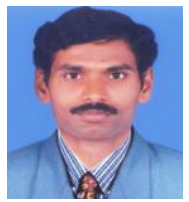

Mr. K.Thiyagarajan, pursed Bachelor of Computer Science, MCA and M.Phil from Bharathidasan University, Thiruchirappaili. Now he is doing Ph.D as a full time research scholar in PG and Research Department of Computer Science, Rajah Serfoji Government College, Thanjavur, Bharathidasan University, Tamilnadu, India. He has having 18 years of teaching and industrial experience. His main research work focuses on IoT, Cloud, Data Analytics, and Wireless Network.

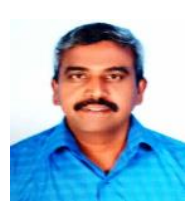

Dr. K. Mohan Kumar, received Master of Compute Science, Ph.D in Computer Science from Bharathidasan University, Tiruchirappalli, India and M.Phil computer science from Manonmaniyam Sundaranar University, Thirunelveli, India. He is currently working as Head, PG and Research Department of Computer Science, Rajah Serfoji Government College, Thanjavur, Tamilnadu, India. His main research work focuses on IoT, Cloud computing, Network Security, Big Data Analytics and Computational Intelligence based education. He has published more than 50 research papers in reputed international journals. He has 25 years of teaching experience and 20 years of Research Experience 